\title{
KARAKTERISTIK, KESESUAIAN, DAN PENGELOLAAN LAHAN BUDIDAYA TAMBAK DI KABUPATEN GRESIK PROVINSI JAWA TIMUR
}

\author{
Utojo, Hasnawi, dan Mudian Paena \\ Balai Penelitian dan Pengembangan Budidaya Air Payau \\ Jl. Makmur Dg. Sitakka No. 129, Maros 90512, Sulawesi Selatan \\ E-mail: litkanta@indosat.net.id
}

(Naskah diterima: 23 Juli 2012; Disetujui publikasi: 19 Juli 2013)

\begin{abstract}
ABSTRAK
Kabupaten Gresik memiliki lahan budidaya tambak yang sangat luas. Lahan tersebut sebagian besar adalah tambak yang bersalinitas rendah (0,14-5,04 ppt), memiliki derajat kemasaman $(\mathrm{pH})$ yang tinggi $(8,08-10,34)$, dan berada jauh dari laut. Hanya lahan yang berada di dekat laut yang bersalinitas payau (10,71-19,97 ppt). Komoditas budidayanya antara lain udang vaname, udang windu, bandeng, nila, dan tawes. Umumnya tambak tersebut dikelola secara tradisional dan produktivitasnya rendah. Oleh karena itu, informasi mengenai karakteristik, kesesuaian, pengelolaan lahan dari penelitian ini diharapkan dapat meningkatkan produktivitas tambak di daerah tersebut. Dalam penelitian ini, penentuan kesesuaian lahan dengan analisis spasial, menggunakan teknologi Sistem Informasi Geografis sangat penting. Topografi lahan umumnya relatif datar dan elevasinya rendah, sebagian berupa rawa dan kawasan tambak sebagian besar berasal dari konversi sawah dengan vegetasi didominasi oleh Sonneratia sp. dan Avicennia sp. Tanah tambak di Kabupaten Gresik tergolong tanah aluvial non sulfat masam yang tidak memiliki potensi kemasaman tanah yang tinggi. Sumber air laut untuk tambak tergolong agak keruh dan salinitas air tambak cukup bervariasi sebagai akibat dari sumber air tawar yang berasal dari Sungai Bengawan Solo dan air hujan. Curah hujan di Kabupaten Gresik sebesar $2.245 \mathrm{~mm} /$ tahun di mana curah hujan yang rendah dijumpai pada bulan Juni sampai Desember. Hasil analisis kesesuaian lahan menunjukkan bahwa luas tambak udang vaname yang ada di Kabupaten Gresik saat ini 31.939 ha, yang tergolong sangat sesuai (kelas S1) 799 ha dan yang cukup sesuai (kelas S2) 31.140 ha. Luas tambak ikan bandeng yang ada di Kabupaten Gresik saat ini 31.940 ha, yang tergolong sangat sesuai (kelas S1) 1.420 ha dan yang cukup sesuai (kelas S2) 30.520 ha. Saluran irigasi tambak mutlak diperlukan untuk memudahkan dalam remediasi tanah dan air melalui pengeringan, perendaman, pembilasan dan pengapuran serta pergantian air. Lokasi yang sesuai dengan komoditas budidaya, dapat mempercepat pertumbuhan dan meningkatkan sintasan komoditas yang dibudidayakan.
\end{abstract}

KATA KUNCl: karakteristik, kesesuaian, pengelolaan lahan tambak, Kabupaten Gresik

ABSTRACT: Characteristics, suitability and management of land for brackishwater ponds culture in Gresik Regency, East Java Province. By: Utojo, Hasnawi, and Mudian Paena

Gresik Regency has a very large area of brackishwater ponds culture land. Most of brackishwater ponds in these areas have low salinity (0.14-5.04 ppt), high acidity level (8.08-10.34) and far from the coast line. Only ponds close to the coast line has saline salinity (10.71-19.97 ppt). In general, brackishwater ponds in the area were managed with traditional system have low productivity in producing several main 
commodities such as tiger prawn, vaname shrimp, milkfish, nile tilapia, and silver carb. This research was conducted to study land characteristics and determine land suitability and land management to increase the productivity of brackishwater ponds in Gresik Regency. Spatial analysis Geographical Information System was used to determine land suitability for brackishwater ponds culture and land management for brackishwater ponds culture. In general, the land topography is flat and the elevation is classified as low, and swamp areas. Brackishwater ponds areas are mainly from convertion of paddy field. The areas are dominated by Sonneratia sp. and Avicennia sp. Soil in brackishwater ponds was dominated by alluvial non-acid sulfate soil distributed in large areas. Source of sea water for brackishwater ponds has moderate turbidity and high variation of salinity due to the presence of freshwater supply from Bengawan Solo River, man made canals and rain waters. The average of rainfall in Gresik Regency is 2,245 $\mathrm{mm} /$ year, where low of rainfall occurs in June until December. Analysis results of land suitability show that the area of vaname shrimp ponds in Gresik Regency is currently as much as 31,939 ha, of which 799 ha is classified as very suitable (S1 class) and 31,140 ha as quite suitable (S2 class). Milkfish ponds in Gresik Regency is currently 31,940 ha, of which 1,420 ha is classified as very suitable (S1 class) and 30,520 ha of quite suitable (S2 class) covering. It is absolutely necessary to facilitate the remmediation of soil and water through drying, soaking, rinsing and liming, as well as water exchange by improving pond irrigation system.

\section{KEYWORDS: characteristic, suitability, brackishwater ponds culture land} management, Gresik Regency

\section{PENDAHULUAN}

Kabupaten Gresik Provinsi Jawa Timur dengan luas $1.192,25 \mathrm{~km}^{2}$ terletak di dataran rendah pesisir utara Pulau Jawa, dengan ketinggian 0-12 meter di atas permukaan laut. Memiliki panjang pesisir kurang lebih $140 \mathrm{~km}$ dan luas wilayah perairan laut $5.773,80 \mathrm{~km}^{2}$ serta posisi geografisnya $7^{\circ}-8^{\circ}$ Lintang Selatan dan $112^{\circ}-113^{\circ}$ Bujur Timur. Batas-batas wilayah administratif yaitu sebelah utara: Laut Jawa; sebelah selatan: Kabupaten Sidoarjo, Kabupaten Mojokerto, dan Kota Surabaya; sebelah barat: Kabupaten Lamongan dan sebelah timur: Selat Madura. Kabupaten Gresik terdiri atas 18 kecamatan, 330 desa, dan 26 kelurahan serta memiliki beberapa kecamatan pesisir antara lain Kecamatan Kebomas, Gresik, Manyar, Bungah, Ujung Pangkah, Sidayu, Panceng, Sangkapura, dan Tambak. Kabupaten Gresik merupakan salah satu kawasan penyanggah Kota Surabaya, selain Kabupaten Bangkalan, Mojokerto, Sidoarjo, dan Lamongan yang dikenal dengan istilah kawasan Gerbang Kertasusila. Kawasan ini berfungsi untuk mengatasi kejenuhan perkembangan kegiatan industri Kota Surabaya dengan tersedianya lahan alternatif kawasan industri yang representatif, kondusif, dan strategis. Wilayah pesisirnya telah difasilitasi dengan pelabuhan besar sehingga Kabupaten ini memiliki akses perdagangan regional, nasional, dan internasional sebagai alternatif terbaik untuk investasi atau penanaman modal.

Kementerian Kelautan dan Perikanan telah menetapkan program industrialisasi budidaya air payau atau tambak untuk udang dan ikan bandeng di beberapa kabupaten di Pulau Jawa yang menunjang program minapolitan dengan merevitalisasi tambak, termasuk Kabupaten Gresik di Provinsi Jawa Timur. Kawasan tambak di Kabupaten ini dipusatkan di Kecamatan Sidayu dengan Kecamatan Dukun, Bungah, Ujung Pangkah, dan Kecamatan Panceng sebagai penyangganya serta komoditas unggulannya yaitu udang vaname dan bandeng. Sumber air utama tambak berasal dari laut, Sungai Bengawan Solo dan sodetannya, Sungai Kali Lamong, dan air tanah (Anonim, 2011).

Suatu kajian untuk menentukan kesesuaian lahan budidaya tambak yaitu karakteristik lahan seperti topografi, tanah, hidrologi, vegetasi, dan iklim serta apabila dikelola secara berlebihan akan berpengaruh terhadap kemampuan penggunaan lahan. Kemampuan lahan untuk menerima beban akibat kegiatan budidaya tambak tidak bersifat statis, dapat menurun akibat akumulasi limbah hasil kegiatan budidaya, dan dapat ditingkatkan melalui pengelolaan lahan secara tepat (Clark, 1992). 
Eksploitasi lahan tambak yang tidak terkendali dan melebihi daya dukung alaminya mengakibatkan rusaknya lingkungan yang berujung pada penurunan produktivitasnya. Evaluasi kesesuaian lahan adalah alat perencanaan penggunaan lahan yang strategis dalam memprediksi keragaan lahan yaitu keuntungan dan kendala yang didapatkan dari penggunaan lahan serta degradasi lingkungan yang akan terjadi karena penggunaan lahan (Hasnawi \& Mustafa, 2010). Kesesuaian lahan merupakan suatu kunci sukses dalam kegiatan akuakultur yang mempengaruhi keberhasilan dan keberlanjutannya (Perez et al., 2003).

Pengelolaan lahan termasuk lahan budidaya tambak yang tepat dapat meningkatkan produktivitasnya tanpa menyebabkan degradasi lingkungan. Setiap jenis lahan memiliki karakteristik tersendiri dan pengelolaannya bersifat spesifik. Penelitian ini bertujuan untuk mengetahui karakteristik, kesesuaian dan pengelolaan lahan budidaya tambak agar produktivitasnya dapat meningkat dan berkelanjutan serta menjadi acuan Pemerintah Daerah Kabupaten Gresik Provinsi Jawa Timur dalam penentuan Rencana Tata Ruang Wilayah khususnya untuk pengembangan budidaya tambak.

\section{BAHAN DAN METODE}

Penelitian dilaksanakan di wilayah pesisir Kabupaten Gresik yaitu di Kecamatan Kebomas, Cerme, Duduk Sampeyan, Manyar, Bungah, dan Sidayu pada bulan April dan Mei 2011.

Kegiatan penelitian ini berupa survai lokasi budidaya tambak dengan memperhatikan morfologi pantai dan keragaman kondisi lokasi budidaya serta vegetasi mangrove sebagai zonasi penyangga. Informasi spasial diperoleh dari hasil pengolahan data dengan teknologi Sistem Informasi Geografis (SIG) yaitu mengintegrasikan data hasil klasifikasi citra ALOS AVNIR 2 tahun 2010 dengan data primer dan data sekunder.

\section{Tahapan Kegiatan}

\section{Koleksi data primer}

Tahapan ini mengumpulkan data primer di lokasi penelitian berupa data topografi lahan yang didapatkan dengan pengamatan morfologi pesisir secara keseluruhan berdasarkan peta satuan unit. Peubah kualitas tanah yang diukur adalah $\mathrm{pH}_{\mathrm{F}}$ dan $\mathrm{pH}_{\mathrm{FOX}}(\mathrm{pH}$ tanah yang dioksidasi dengan hidrogen peroksida $\left(\mathrm{H}_{2} \mathrm{O}_{2}\right)$ $30 \%$ ) dengan $\mathrm{pH}$ meter serta potensial redoks dengan redoxmeter. Penentuan titik-titik pengambilan contoh tanah di lokasi penelitian ditentukan secara acak, sistematik dan representatif, mengacu pada peta satuan unit. Contoh tanah diambil pada kedalaman 0-0,2 m dan 0,2-0,4 $\mathrm{m}$ dari permukaan tanah. Contoh tanah dimasukkan dalam kantong plastik yang berlabel kode lokasi dan tanggal pengambilannya, selanjutnya dimasukkan dalam cold box berisi es kering dan dianalisis di Laboratorium Tanah Balai Penelitian dan Pengembangan Budidaya Air Payau di Maros.

Sebelum dianalisis, contoh tanah di-oven pada suhu $80^{\circ} \mathrm{C}-85^{\circ} \mathrm{C}$ selama $48 \mathrm{jam}$. Setelah kering, contoh tanah dihaluskan dengan cara ditumbuk pada lumpang porselin dan diayak dengan ukuran lubang $2 \mathrm{~mm}$. Peubah kualitas tanah yang dianalisis berupa tekstur tanah dengan metode hidrometer (Bouyoucos, 1962), bahan organik dengan metode Ignition loss (Melville, 1993), $\mathrm{PO}_{4}$ dengan metode Olsen, total nitrogen ( $\mathrm{N}$ total) dengan metode Kjedhal (Sulaeman et al., 2005), Fe dan Al dengan spektrofotometer serapan atom (SSA).

Data hidrologi yang diukur adalah pasang surut dan kualitas air. Pasang surut diukur di perairan Laut Utara Jawa berbatasan dengan Kabupaten Lamongan. Pasang surut diukur dengan papan pengamat berskala $1 \mathrm{~cm}$ pada setiap jam selama 39 jam. Kualitas air dan contoh air diukur dan diambil di wilayah tambak, sungai dan laut. Pengukuran kualitas air dan pengambilan contoh air di tambak, titik dan waktunya bersamaan dengan pengukuran kualitas tanah dan pengambilan contoh tanah. Peubah kualitas air yang diukur di lokasi penelitian berupa suhu, $\mathrm{pH}$, salinitas, dan oksigen terlarut dengan Hydrolab Minisonde. Contoh air diambil di tambak dengan Kemmerer Water Sampler, dan dimasukkan dalam botol yang berlabel kode lokasi dan tanggal pengambilannya, selanjutnya dimasukkan dalam cold box berisi es kering dan dianalisis di Laboratorium Air Balai Penelitian dan Pengembangan Budidaya Air Payau di Maros. Peubah kualitas air yang dianalisis berupa $\mathrm{NH}_{4}, \mathrm{NO}_{2}$, $\mathrm{NO}_{3}, \mathrm{PO}_{4}$, bahan organik total, kekeruhan, dan padatan tersuspensi total mengikuti petunjuk Parson et al. (1989).

Jenis-jenis vegetasi mangrove diidentifikasi dengan cara mencatat setiap jenis vege- 
tasi yang terdapat di lokasi penelitian mulai dari pantai sampai ke arah daratan yang masih terdapat tambak, dan diklasifikasikan sampai pada tingkat suku dengan buku petunjuk Blaso (1984) dan Bengen (2004). Setiap titik pengukuran dan pengambilan contoh di lokasi penelitian ditentukan posisinya dengan Global Positioning System (GPS). Pengukuran dan pengambilan contoh di lokasi penelitian sebanyak 57 titik yang tersebar di 10 kecamatan berdasarkan luas, kondisi, dan tingkat keragaman lokasi (Gambar 1).

\section{Koleksi data sekunder}

Tahapan ini mengumpulkan data sekunder berupa laporan dan pustaka hasil penelitian serta hasil pengamatan data meteorologi dari berbagai instansi terkait. Peta yang dikumpulkan berupa peta jenis tanah skala 1:250.000 Provinsi Jawa Timur, peta curah hujan tahunan Provinsi Jawa Timur, peta kelerengan Kabupaten Gresik, peta Rupabumi Indonesia skala 1:50.000 dengan nomor indeks 1509-
324 (Klayar), 1609-1 13 (Ujung Pangkah), 1509322 (Prupuk), 1609-111 (Sidayu), 1608-433 (Bungah), 1608-431 (Cerme), dan peta administrasi Kabupaten Gresik.

Menggunakan data citra ALOS (Advanced Land Observing Satellite) AVNIR-2 (Advanced Visible and Near Infrared Radiometer type 2) akuisisi tahun 2010 yang telah terkoreksi secara radiometrik, geometrik, dan teregistrasi. Penajaman citra dengan cara modifikasi kontras data citra dengan bantuan program Er Mapper 7.1. Untuk mengurangi pengaruh cerah atau gelap dari gambar lokasi penelitian dalam citra dengan penapisan citra. Data citra landsat ALOS memiliki empat kanal, dan direduksi berdasarkan metode pemilihan kombinasi kanal spektral menjadi tiga kanal yaitu kombinasi kanal 321 (Red Green Blue) dari sensor landsat ALOS. Hasil analisis, tampak secara jelas perbedaan spektral untuk setiap tutupan lahan di wilayah daratan dan perairan. Kemudian dilakukan klasifikasi untuk membedakan penggunaan lahan secara tepat dan sesuai.

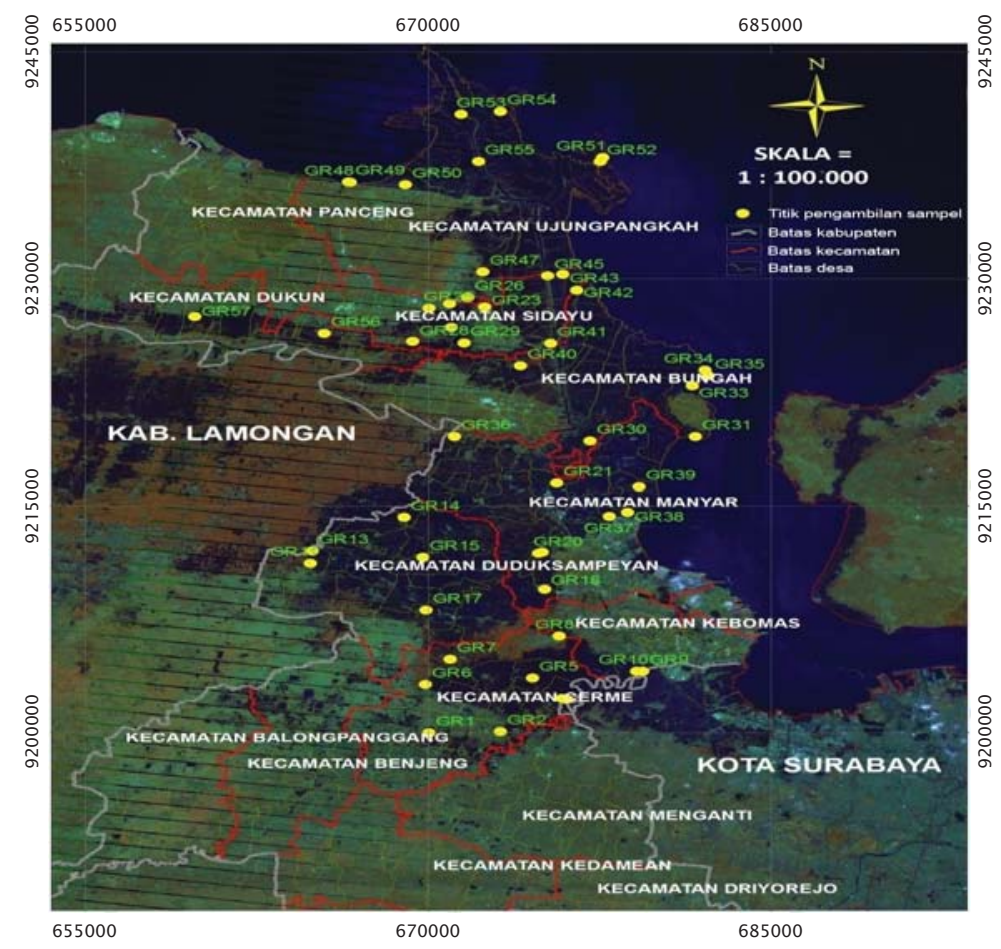

Gambar 1. Peta sebaran titik pengukuran dan pengambilan contoh untuk kesesuaian lahan budidaya tambak di Kabupaten Gresik Provinsi Jawa Timur

Figure 1. Map of sampling station distribution for land suitability of ponds culture at Gresik Regency East Java Province 
Informasi dari peta dasar berupa morfologi dan garis pantai, sungai, garis batas wilayah, jalan, lumpur (sedimentasi), mangrove, penggunaan lahan, sebaran penduduk, letak, dan nama lokasi, garis kontur atau ketinggian daratan dan kedalaman laut. Kriteria untuk skala nilai dan bobot kesesuaian lahan budidaya tambak dilakukan secara kuantitatif, mengacu pada persyaratan yang disarankan oleh Poernomo (1992).

Evaluasi kesesuaian lahan dengan metode PATTERN (Planning Assisstance Through Technical Evaluation of Relevant Numbers) untuk menghitung tingkat relatif dari kontribusi di setiap faktor lahan geografis secara spasial dalam peta kesesuaian lahan budidaya tambak (Karthik et al., 2005). Pada metode ini setiap kategori di setiap faktor ditentukan dengan angka skor dan total skor dihitung sebagai jumlah bobot dari setiap skor kategori (Karthik et al., 2005).

\section{Pengolahan data}

Data sekunder dan primer diolah serta dianalisis secara spasial dalam SIG untuk menentukan kesesuaian lahan budidaya tambak. Pada proses analisis dengan program ArcView 3.3, data primer hasil survai di setiap pengamatan dimasukkan dalam peta dasar digital dan menginterpolasi di setiap titik koordinat pengamatan menjadi area (polygon) dengan metode Nearest Neighbour (Morain, 1999). Hasil interpolasi setiap pengamatan, disusun secara spasial dengan tingkat bobot dan skala nilai, kemudian di-overlay (tumpang susun) untuk mendapatkan peta lokasi budidaya tambak dengan tingkat sangat sesuai, cukup sesuai, sesuai marjinal dan tidak sesuai, masing-masing disertai luasannya. Pengelolaan lahan yang direkomendasikan berdasarkan pada karakteristik lahan dan disesuaikan dengan tingkat teknologi dan komoditas yang diaplikasikan di tambak.

\section{HASIL DAN BAHASAN}

\section{Kondisi Umum}

Sebagian besar topografi lahan Kabupaten Gresik relatif datar dan elevasinya rendah sekitar $0-2 \%$. Wilayah pesisir dengan kemiringan lahan yang rendah ini menyebar dan memanjang dari utara ke selatan, sebagian kecil di bagian utara berbukit yaitu di Kecamatan Panceng dan Ujung Pangkah. Lahan di wilayah ekosistem pesisir berupa tambak hasil konversi mangrove, lahan di wilayah ekosistem daratan berupa rawa dan tambak hasil konversi sawah serta sebagian tambak dan sawah dialihfungsikan menjadi lokasi pemukiman dan industri seperti di Kecamatan Manyar, Kebomas, Cerme, dan Duduk Sampeyan.

Berdasarkan laporan Dinas Kelautan, Perikanan dan Peternakan Kabupaten Gresik tahun 2009, Kabupaten Gresik memiliki lahan tambak air payau dan tambak air tawar. Luas tambak air payau 17.835 ha dan tambak air tawar 14.629 ha, masing-masing produksinya 14.958 ton dan 15.498 ton. Komoditas tambak air payau yaitu udang windu, udang vaname, bandeng, dan kerapu, serta tambak air tawar yaitu udang windu, udang vaname, bandeng, tawes, dan nila. Kedua lahan tersebut dikelola secara tradisional dan tradisional plus sistem monokultur dan polikultur (Anonim, 2009). Hasil survai dan analisis kualitas tanah, didapatkan bahwa di tambak air payau bertekstur lempung liat berpasir hingga lempung berpasir, jenis vegetasi mangrovenya didominasi Avicennia sp. dan Sonneratia sp., serta di tambak air tawar bertekstur lempung berliat hingga lempung liat berpasir dan vegetasinya berasosiasi dengan vegetasi daratan seperti jenis Tamarindus sp., Acanthus sp., Hibiscus sp., dan Euchornia sp.

\section{Karakteristik Lahan}

Dari 18 kecamatan di Kabupaten Gresik, hanya 8 kecamatan yang lahan tambaknya dikarakterisasi yaitu di Kecamatan Cerme, Kebomas, Duduk Sampeyan, Manyar, Sidayu, Bungah, Ujung Pangkah, dan Dukun. Telah disebutkan sebelumnya bahwa lahan yaitu suatu lingkungan biofisik yang penyusunnya terdiri atas topografi, tanah, hidrologi, vegetasi, dan iklim. Kemampuan lahan dapat menurun, jika terjadi kegiatan budidaya tambak atau aktivitas lain yang berlebihan dan dapat ditingkatkan kemampuannya melalui pengelolaan lahan secara tepat. Oleh karena itu, setiap penyusun dari lahan tersebut akan dibahas pada bagian berikut ini.

\section{Topografi}

Pada umumnya kawasan pesisir dan daratan di Kabupaten Gresik memiliki topografi yang relatif rendah dan datar, hanya di Kecamatan Panceng dan Ujung Pangkah sebagian lahannya berbukit dan tanahnya berkapur. Tambak di areal ekosistem pesisir, elevasinya landai, dan terjangkau oleh pasang surut serta tambak 
di areal ekosistem daratan, airnya tawar. Lahan rawa atau pasang surut yang tidak rata, bergelombang atau berbukit tidak layak dibangun untuk lokasi tambak karena memerlukan biaya yang mahal dalam memapas dan menimbun tanah, lahan pasang surut yang memiliki kemiringan dan elevasi sangat landai merupakan lokasi yang ideal bagi pembangunan tambak serta dalam pengelolaan tambaknya memerlukan biaya yang relatif murah (Chanratchakool et al., 1995).

\section{Tanah}

Tekstur tanah dan kualitas tanah di Kabupaten Gresik dapat dilihat pada Tabel 1. Tekstur tanah tambak di Kabupaten Gresik didominasi oleh fraksi liat dan lempung yang berasal dari hulu sungai, fraksi pasir dan debu berasal dari laut dan sebagian dari tambak yang sedikit mangrovenya. Budidaya tambak ikan dan udang yang dikelola secara tradisional dan tradisional plus, fraksi liat tanah ini diperlukan sebagai tempat perlekatan dan pertumbuhan kelekap dan lumut untuk pakan alaminya. Tanah tambak yang bertekstur pasir berlempung dan pasir memiliki tingkat porositas yang tinggi sehingga tambak tidak dapat menahan air. Menurut llyas et al. (1987), fraksi liat, lempung, lempung berliat, lempung liat berdebu, lempung berdebu dan lempung liat berpasir adalah tekstur tanah tambak yang baik untuk budidaya ikan, dan udang.

Selisih nilai $\mathrm{pH}_{\mathrm{F}}$ dan $\mathrm{pH}_{\mathrm{FOx}}$ untuk menentukan potensi kemasaman tanah. Semakin besar nilai selisihnya, semakin tinggi nilai potensi kemasamannya. Selisih nilai $\mathrm{pH}_{\mathrm{F}}$ dan $\mathrm{pH}_{\mathrm{Fox}}$ tanah tambak di Kabupaten Gresik sampai kedalaman 0,4 m sangat kecil dan relatif sama. Rendahnya potensi kemasaman tanah sangat ditentukan oleh rendahnya bahan organik yang didapatkan. Hanya sebagian tambak di lahan mangrove yang didapatkan memiliki potensi kemasaman tanah yang tinggi yaitu di Kecamatan Bungah dan Manyar. Potensi kemasaman tanah tambak yang rendah didapatkan di semua kecamatan yang masuk wilayah ekosistem daratan.

Potensial redoks tanah menggambarkan kondisi tanah tambak yang tereduksi atau teroksidasi. Data potensial redoks tanah tambak di Kabupaten Gresik sampai kedalaman 0,4 m bermuatan negatif artinya tambak selalu tergenang dan terdapat lumpur hitam beracun sedalam 0,4 m serta kondisi tanah tambaknya tereduksi (anaerob). Kondisi tanah tambak yang baik yaitu saat persiapan, lumpur hitam dibuang dan tanah dikeringkan agar teroksidasi untuk memperbaiki sifat biofisik tanah, meningkatkan mineralisasi bahan organik dan menghilangkan senyawa-senyawa beracun berupa hidrogen sulfida $\left(\mathrm{H}_{2} \mathrm{~S}\right)$, amonia $\left(\mathrm{NH}_{3}\right)$, nitrit $\left(\mathrm{NO}_{2}\right)$, dan metan $\left(\mathrm{CH}_{4}\right)$.

Konsentrasi fosfat tanah tambak di Kabupaten Gresik bervariasi. Fosfat sebagai unsur esensial bagi tanaman dan algae akuatik serta produktivitas primer yang dapat meningkatkan produksi ikan di tambak (Effendi, 2003). Ketersediaan fosfat tanah $>60 \mathrm{mg} / \mathrm{L}$, tergolong baik untuk kesuburan perairan tambak (Karthik et al., 2005). Fosfat tanah tambak yang tinggi (3.097,10 mg/L), didapatkan di Desa Tambak Beras Kecamatan Cerme, letaknya jauh dari laut yang berbatasan dengan sawah dan pemukiman. Tingginya fosfat tanah tambak lebih banyak dipengaruhi oleh limbah pupuk pertanian dan limbah rumah tangga.

Kandungan bahan organik tanah tambak di Kabupaten Gresik sampai kedalaman 0,4 m relatif rendah. Tingginya bahan organik tanah didapatkan pada tambak Desa Randu Boto, Kecamatan Sidayu yaitu 11,53\%. Tanah tambak di desa tersebut bukan tergolong tanah gambut karena bahan organiknya masih lebih rendah dari 20\%. Menurut Boyd et al. (2002), kisaran bahan organik tanah yang baik untuk tambak 1,7-5,2\%. Bahan organik tanah tambak yang rendah disertai dengan $\mathrm{N}$-total yang sangat rendah berdampak pada sangat tingginya rasio $\mathrm{C}: \mathrm{N}$. Rasio $\mathrm{C}: \mathrm{N}$ yang ideal untuk tambak 8:1-12:1 (Boyd, 2008).

Kandungan Fe dan Al tanah tambak di Kabupaten Gresik umumnya rendah, tingginya Fe tanah pada kedalaman 0,4 m yaitu $5.235,0$ $\mathrm{mg} / \mathrm{L}$, didapatkan pada tambak mangrove yang direklamasi. Menurut Poernomo (1992), tambak yang dibangun di areal mangrove, tanahnya mengandung pirit $\left(\mathrm{FeS}_{2}\right)$. Selesai konstruksi, tambak dikeringkan, ion besi fero teroksidasi menjadi ion besi feri dalam bentuk ferihidroksida $\mathrm{Fe}(\mathrm{OH})_{3}$ yang mengendap di dasar tanah tambak berwarna karat besi kemerahan. Banyaknya ion besi feri $\left(\mathrm{Fe}^{3+}\right)$ bersumber dari banyaknya pirit dalam tanah tambak mangrove yang teroksidasi.

\section{Hidrologi}

\section{Kualitas air}

Keberadaan laut, Sungai Bengawan Solo, dan sodetannya di Kabupaten Gresik, yang 


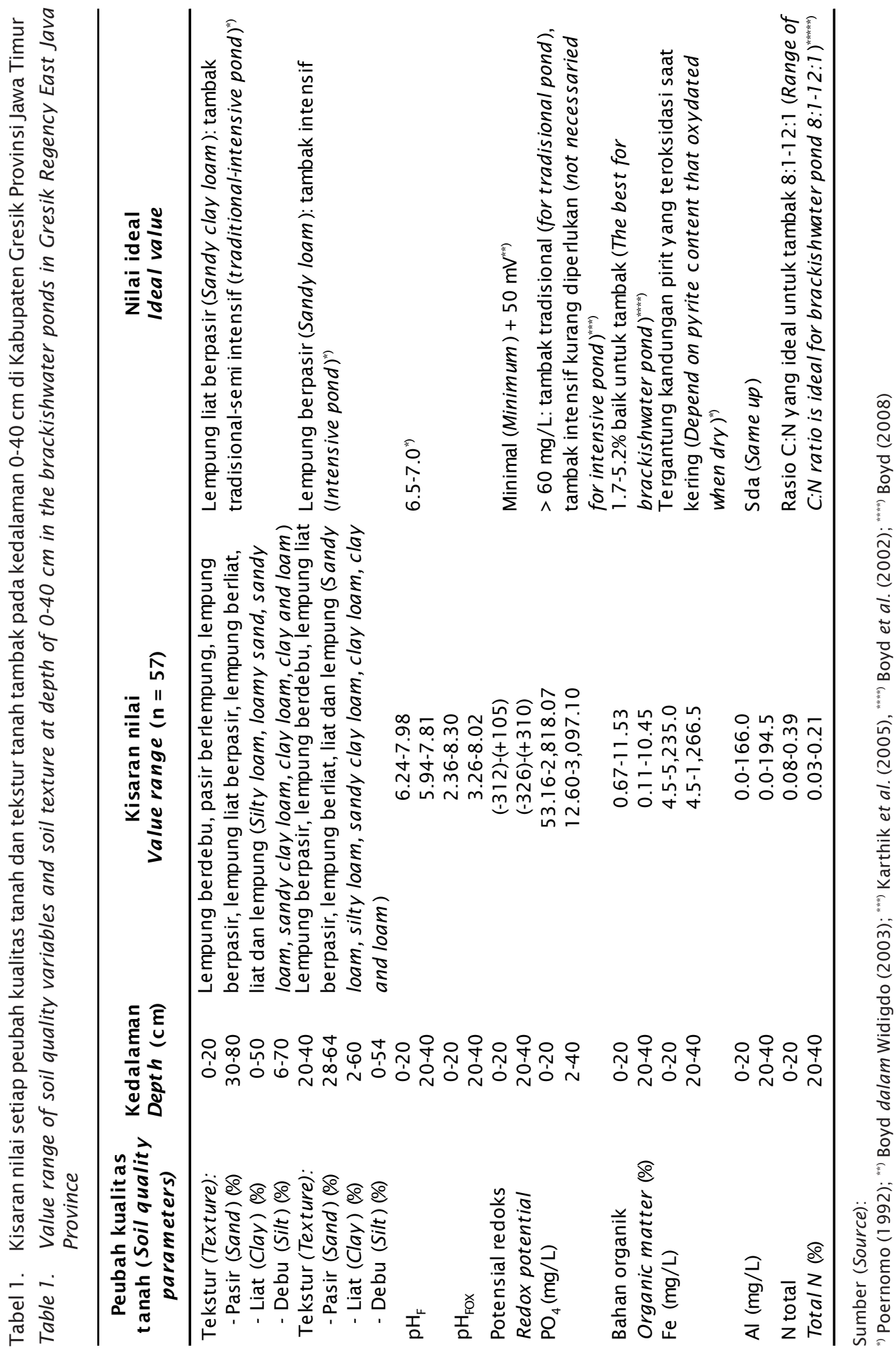


terbagi dalam beberapa cabang sungai dan muara sungai tersebut dapat memberikan salinitas air tambak cukup bervariasi seperti terlihat pada Tabel 2 . Kisaran salinitas air laut 26,55-28,11 ppt, muara sungai 18,82-25,15 ppt, dan Sungai Bengawan Solo 0,1 1-6,73 ppt serta sebagian air tanah dengan kedalaman $25 \mathrm{~m}$ dan $30 \mathrm{~m}$, masing-masing salinitasnya 10,37 ppt dan 13,28 ppt. Di Kabupaten Gresik memiliki tambak air payau salinitasnya 10,7119,97 ppt dan tambak air tawar salinitasnya 0,14-5,04 ppt. Salinitas optimum untuk budidaya udang windu dan vaname 15-25 ppt (Poernomo, 1988; Menz \& Blake, 1980), udang vaname tumbuh optimum pada salinitas 15-20 ppt (Bray et al., 1994) dan ikan bandeng tumbuh baik pada salinitas 12-20 ppt (Ahmad et al., 1998).

Suhu air tambak di Kabupaten Gresik $27,88^{\circ} \mathrm{C}-35,69^{\circ} \mathrm{C}$. Suhu air yang tinggi, didapatkan di tambak dangkal berbatasan dengan sawah dan pemukiman serta saat pengukuran pada sore hari yaitu di Desa Dungus, Kecamatan Cerme. Suhu air yang layak untuk budidaya udang windu $26^{\circ} \mathrm{C}-32^{\circ} \mathrm{C}$ dengan optimumnya $29^{\circ} \mathrm{C}-30^{\circ} \mathrm{C}$ (Poernomo, 1988). Suhu air yang baik untuk budidaya bandeng yaitu $28^{\circ} \mathrm{C}$ dan $30^{\circ} \mathrm{C}$ (Ahmad et al., 1998). Suhu air optimum untuk budidaya udang vaname $25^{\circ} \mathrm{C}-35^{\circ} \mathrm{C}$ (Ponce-Palatox et al., 1997).

Nilai pH air tambak di Kabupaten Gresik 8,08-10,34, masih baik untuk budidaya tambak. Tingginya $\mathrm{pH}$ air tambak karena jenis tanahnya aluvial non sulfat masam dan rendahnya bahan organik tanah. Kisaran $\mathrm{pH}$ air yang baik untuk budidaya udang windu 7,5-8,5 dengan optimum 8,0-8,5 (Poernomo, 1988). Menurut Effendi (2003), sebagian besar biota akuatik sensitif terhadap perubahan $\mathrm{pH}$ dan menyukai $\mathrm{pH} 7-8,5$. Pengaruh langsung $\mathrm{pH}$ rendah yaitu udang menjadi kropos, selalu lembek dan amonium terionisasi serta tidak toksik pada organisme akuatik, pada $\mathrm{pH}$ tinggi yaitu ammonia

Tabel 2. Kisaran nilai setiap peubah kualitas air tambak di Kabupaten Gresik Provinsi Jawa Timur

Table 2. The range value of water quality variables in the brackishwater ponds in Gresik Regency East Java Province

\begin{tabular}{|c|c|c|c|}
\hline $\begin{array}{l}\text { Peubah } \\
\text { Variables }\end{array}$ & $\begin{array}{l}\text { Satuan } \\
\text { Unit }\end{array}$ & $\begin{array}{l}\text { Kisaran nilai } \\
\text { Value range }(\mathrm{n}=65)\end{array}$ & $\begin{array}{l}\text { Nilai ideal } \\
\text { Ideal value }\end{array}$ \\
\hline \multicolumn{4}{|l|}{ Salinitas (Salinity): } \\
\hline - Laut (Sea) & ppt & $26.55-28.11$ & $30-35^{*}$ \\
\hline - Muara sungai (Estuarine) & ppt & $18.82-25.15$ & $25-30 *$ \\
\hline -Sungai (River) & ppt & $0.11-6.73$ & $10-25^{*}$ \\
\hline - Tambak air payau (Brackishwater pond) & ppt & 10.71-19.97 & $15-25^{*}$ \\
\hline - Tambak air tawar (Freshwater pond) & ppt & $0.14-5.04$ & $0-5.0^{* * * * m}$ \\
\hline Suhu (Temperature) & ${ }^{\circ} \mathrm{C}$ & $27.88-35.69$ & $29-31^{*}$ \\
\hline $\mathrm{pH}$ & & $8.08-10.34$ & $7.0-8.5^{* m}$ \\
\hline Oksigen terlarut (Dissolved oxygen) & $\mathrm{mg} / \mathrm{L}$ & 6.27-8.98 & $4-7^{* 1}$ \\
\hline $\mathrm{NH}_{3}$ & $\mathrm{mg} / \mathrm{L}$ & $0.4234-5.0082$ & $0.30^{* * 1}$ \\
\hline $\mathrm{NO}_{2}$ & $\mathrm{mg} / \mathrm{L}$ & $0.0092-0.0981$ & $0.25^{*}$ \\
\hline $\mathrm{NO}_{3}$ & $\mathrm{mg} / \mathrm{L}$ & $0.0702-3.7224$ & $0.008^{* * 1}$ \\
\hline $\mathrm{PO}_{4}$ & $\mathrm{mg} / \mathrm{L}$ & $0.0032-0.9410$ & $0.015^{* *}$ \\
\hline Kekeruhan (Turbidity) & NTU & $2.39-327.25$ & $20-30 *$ \\
\hline $\begin{array}{l}\text { Padatan tersuspensi total } \\
\text { Total suspended solid }\end{array}$ & $\mathrm{mg} / \mathrm{L}$ & $15-684$ & $<25^{* * *}$ \\
\hline Bahan organik total (Total organic matter) & $\mathrm{mg} / \mathrm{L}$ & $4.50-27.56$ & $29.50 *$ \\
\hline
\end{tabular}


tidak terionisasi bersifat toksik dan lebih mudah terserap ke dalam tubuh organisme akuatik dibandingkan dengan amonium.

Kebutuhan organisme akuatik akan oksigen terlarut sangat bervariasi tergantung pada jenis, stadium dan aktivitasnya. Oksigen terlarut di tambak Kabupaten Gresik 6,27-8,98 $\mathrm{mg} / \mathrm{L}$ dan kisaran nilai tersebut masih baik untuk kegiatan budidaya tambak. Menurut Poernomo (1992), kecepatan dan besarnya konsumsi oksigen meningkat seiring dengan meningkatnya suhu air serta udang tumbuh pesat pada suhu $30^{\circ} \mathrm{C}-31^{\circ} \mathrm{C}$. Batas oksigen terlarut untuk udang windu 3-10 mg/L dan optimumnya 4-7 mg/L (Poernomo, 1989). Menurut Hopkins et al. (1991), oksigen terlarut yang mematikan udang vaname adalah $1 \mathrm{mg} / \mathrm{L}$.

Kandungan molekul amonia $\left(\mathrm{NH}_{3}\right)$ di tambak Kabupaten Gresik 0,4234-5,0082 mg/L. Tingginya amonia didapatkan dari hasil pemecahan nitrogen organik limbah pupuk urea sawah dan reduksi gas nitrogen limbah domestik pemukiman. Batas kelayakan amonia untuk budidaya udang $0,25 \mathrm{mg} / \mathrm{L}$ dengan optimumnya $0 \mathrm{mg} / \mathrm{L}$ (Poernomo, 1992). Menurut Effendi (2003), amonia jarang didapatkan di perairan yang cukup pasokan oksigen dan amonia yang tinggi terdapat di dasar perairan tanpa oksigen. Amonia bebas $\left(\mathrm{NH}_{3}\right)$ tidak dapat terionisasi dan bersifat toksik terhadap organisme akuatik, sedangkan amonium $\left(\mathrm{NH}_{4}^{+}\right)$dapat terionisasi dan tidak bersifat toksik terhadap organisme akuatik.

Kandungan nitrit di tambak Kabupaten Gresik 0,0092-0,0981 mg/L. Kisaran nilai tersebut masih baik untuk media budidaya tambak. Nitrit di perairan relatif kecil karena cepat teroksidasi menjadi nitrat. Nitrit bersifat toksik terhadap ikan atau udang, karena mengoksidasikan besi ( $\mathrm{Fe}$ ) di dalam hemoglobin atau hemocyanin sehingga kemampuan darah ikan atau udang untuk mengikat oksigen terlarut sangat lemah (Poernomo, 1988). Batas nitrit untuk media budidaya tambak udang $0,25 \mathrm{mg} / \mathrm{L}$ dengan optimumnya 0 mg/L (Poernomo, 1992).

Kandungan nitrat di perairan tambak Kabupten Gresik 0,0702-3,7224 mg/L, masih baik untuk media budidaya tambak. Banyak sedikitnya nitrat di perairan, tergantung dari kecepatan proses nitrifikasi oleh bakteri nitrifikasi, nilai $\mathrm{pH}$, kandungan oksigen terlarut dan suhu. Nitrat tidak bersifat toksik terhadap organisme akuatik dan lebih dari $0,2 \mathrm{mg} / \mathrm{L} \mathrm{di}$ perairan, berakibat eutrofikasi (Effendi, 2003).
Kandungan fosfat $\left(\mathrm{PO}_{4}\right)$ di tambak Kabupaten Gresik 0,0032-0,9410 mg/L, masih baik untuk media budidaya tambak. Tingginya fosfat, didapatkan di tambak Desa Dungus Kecamatan Cerme akibat limbah pupuk pertanian dan limbah domestik pemukiman. Kisaran nilai fosfat yang didapatkan tergolong tingkat kesuburan rendah dan tinggi. Menurut Effendi (2003), perairan yang memiliki fosfat total 0 $0,02 \mathrm{mg} / \mathrm{L}$, tingkat kesuburannya rendah dan fosfat total 0,051-1,0 mg/L, tingkat kesuburannya tinggi.

Kandungan bahan organik total di tambak Kabupaten Gresik 4,50-27,56 mg/L dengan padatan tersuspensi total $15-684 \mathrm{mg} / \mathrm{L}$ dan kekeruhan 2,39-327,25 NTU. Kisaran nilai bahan organik dan padatan tersuspensi total yang didapatkan masih baik untuk media budidaya tambak. Padatan tersuspensi berkorelasi positif dengan kekeruhan, semakin tinggi nilai padatan tersuspensi, nilai kekeruhan juga semakin tinggi. Tingginya nilai padatan tersuspensi total dan kekeruhan akibat lumpur halus, didapatkan di tambak Desa Randu Boto, Kecamatan Sidayu dekat muara Sungai Bengawan Solo pada saat hujan. Bahanbahan tersuspensi di perairan alami tidak bersifat toksik, jika berlebihan dapat meningkatkan nilai kekeruhan yang mengganggu proses fotosintesis dan pernafasan organisme akuatik (Effendi, 2003). Bahan organik total perairan di atas $26 \mathrm{mg} / \mathrm{L}$, tergolong subur (Reid, 1961).

\section{Pasang Surut}

Kisaran pasang surut di Kabupaten Gresik $60-180 \mathrm{~cm}$ dengan tunggang pasang $120 \mathrm{~cm}$ (Gambar 2). Kondisi seperti ini cukup mempengaruhi kuantitas dan kualitas air budidaya tambak. Laju kecepatan aliran air sumber selama pasang tinggi dipengaruhi oleh frekuensi amplitudo pasang, kontur tanah dan elevasi. Menurut Poernomo (1992), pelaksanaan budidaya tambak dengan pergantian air secara gravitasi saat pasang, lokasi dengan elevasi sedang dan dapat diairi saat pasang tinggi serta dapat dikeringkan saat surut terendah merupakan lokasi yang ideal untuk pembangunan unit tambak.

\section{Vegetasi}

Jenis vegetasi mangrove yang didapatkan di Kabupaten Gresik berjumlah 28 jenis, 19 marga, dan 16 suku (Tabel 3). Karakteristik habitat hutan mangrove yaitu tumbuh di daerah 


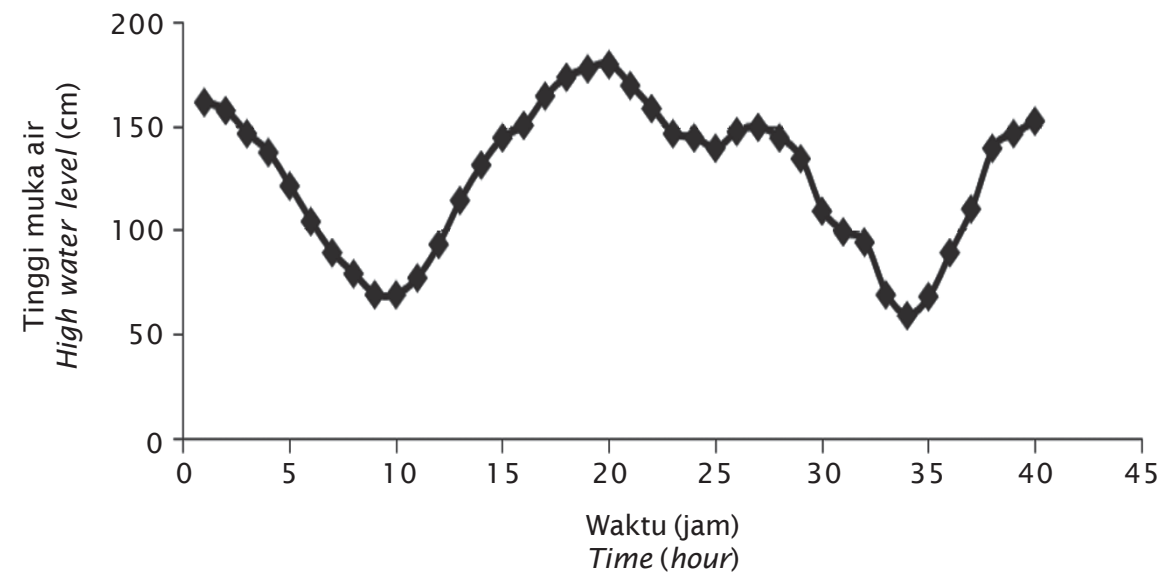

Gambar 2. Pasang surut di kawasan pesisir Kabupaten Gresik, Provinsi Jawa Timur

Figure 2. Tidal range in the coastal area of Gresik Regency, East Java Province

intertidal yang tanahnya berlumpur, berlempung atau berpasir, menerima pasokan air tawar dan air payau (2-22 ppt) hingga asin (mencapai $38 \mathrm{ppt}$ ), dan terlindung dari gelombang besar dan arus pasang surut yang kuat (Bengen, 2004).

Dari 19 marga vegetasi mangrove di Kabupaten Gresik terdapat 8 marga vegetasi mangrove halopitik berbunga yang mampu tumbuh di dasar perairan yang asin yaitu Avicennia sp., Sonneratia sp., Rhizophora sp., Bruguiera sp., Ceriops sp., Xylocarpus sp., Lummitzera sp., dan Aegiceras sp. Terdapat 5 marga vegetasi mangrove yang mampu beradaptasi di dasar perairan anaerob yaitu Avicennia sp., Xylocarpus sp., Sonneratia sp., Lumnitzera sp., dan Rhizophora sp. Kelompok vegetasi ini adalah vegetasi tetap pada habitat mangrove, mampu membentuk tegakan murni, memiliki bentuk akar dan viviparitas yang menentukan ciri penyusun komunitas mangrove. Terdapat 3 marga vegetasi daratan yang berasosiasi dengan mangrove yaitu Acanthus sp., Hibiscus sp., dan Euchornia sp. Kelompok vegetasi ini merupakan vegetasi sementara yang hidup beradaptasi pada habitat mangrove.

\section{Iklim}

Musim kemarau dan musim hujan di Kabupaten Gresik sangat penting peranannya dalam memprediksi berapa kali musim tanam dan berproduksi per tahunnya. Unsur iklim yang paling besar pengaruhnya terhadap kegiatan budidaya tambak yaitu curah hujan.
Curah hujan yang rendah terjadi pada JuniDesember, curah hujan yang tinggi terjadi pada Januari-Mei. Secara umum rata-rata curah hujan di Kabupaten Gresik 2.245 mm/tahun atau rata-rata $187,08 \mathrm{~mm} /$ bulan, cukup baik untuk kegiatan budidaya tambak.

\section{Kesesuaian dan Pengelolaan Lahan}

\section{Kesesuaian Lahan}

Hasil analisis kesesuaian lahan menunjukkan bahwa tambak udang vaname di Kabupaten Gresik saat ini seluas 31.939 ha, yang sangat sesuai (kelas S1) 799 ha di Kecamatan Bungah, dan yang cukup sesuai (kelas S2) 31.140 ha tersebar di Kecamatan Ujung Pangkah, Sidayu, Manyar, Duduk Sampeyan, dan Kecamatan Cerme (Gambar 3). Tambak ikan bandeng di Kabupaten Gresik saat ini seluas $31.940 \mathrm{ha}$, yang sangat sesuai (kelas S1) 1.420 ha di Kecamatan Bungah dan Manyar, dan yang cukup sesuai (kelas S2) 30.520 ha tersebar di Kecamatan Ujung Pangkah, Sidayu, Duduk Sampeyan, dan Kecamatan Cerme (Gambar 4). Lahan tambak yang sangat sesuai untuk kegiatan budidaya udang vaname atau ikan bandeng dengan teknologi semi intensif sampai intensif dan yang cukup sesuai untuk teknologi tradisional sampai semi intensif.

\section{Pengelolaan Lahan}

Faktor pembatas lahan budidaya tambak di Kabupaten Gresik yaitu kandungan bahan organik dan unsur nitrogen total tanah tambak 
Tabel 3. Jenis vegetasi mangrove yang didapatkan di kawasan pesisir Kabupaten Gresik Provinsi Jawa Timur

Table 3. Species of mangrove vegetation found in coastal area of Gresik Regency, East Java Province

\begin{tabular}{|c|c|c|c|}
\hline $\begin{array}{l}\text { Suku } \\
\text { Family }\end{array}$ & $\begin{array}{l}\text { Marga } \\
\text { Genera }\end{array}$ & $\begin{array}{l}\text { Jenis } \\
\text { Species }\end{array}$ & $\begin{array}{c}\text { Komunitas mangrove } \\
\text { di lokasi } \\
\text { Community of } \\
\text { mangrove in location }\end{array}$ \\
\hline Avicenniaceae & Avicennia & $\begin{array}{l}\text { Avicennia alba } \\
\text { Avicennia marina }\end{array}$ & Melimpah (Abundance) \\
\hline Ac anthaceae & Ac anthus & Acanthus ilicifolius & Terbatas (Limited) \\
\hline Arecaceae & Nypa & Nypa fruticans & Terbatas (Limited) \\
\hline Combretaceae & Lumnitzera & $\begin{array}{l}\text { Lumnitzera littorea } \\
\text { Lumnitzera racemosa }\end{array}$ & Sedang (Moderate) \\
\hline Euphorbiaceae & Excoecaria & Excoecaria agallocha & Terbatas (Limited) \\
\hline Fabaceae & Tamarindus & Tamarindus indica & Terbatas (Limited) \\
\hline Leguminosae & Intsia & Intsia bijuga & Terbatas (Limited) \\
\hline Malvaceae & $\begin{array}{l}\text { Hibiscus } \\
\text { Thespesia }\end{array}$ & $\begin{array}{l}\text { Hibiscus tiliaceus } \\
\text { Thespesia populnea }\end{array}$ & $\begin{array}{l}\text { Terbatas (Limited) } \\
\text { Terbatas (Limited) }\end{array}$ \\
\hline Meliaceae & Xylocarpus & $\begin{array}{l}\text { Xylocarpus granatum } \\
\text { Xylocarpus moluccensis }\end{array}$ & Terbatas (Limited) \\
\hline Myrsinaceae & Aegiceras & Aegiceras corniculatum & Sedang (Moderate) \\
\hline Polypodiace ae & Acrostichum & Acrostichum aureum & Terbatas (Limited) \\
\hline Pontederiace ae & Euchornia & Euchornia crasipes & Melimpah (Abundance) \\
\hline \multirow[t]{3}{*}{ Rhizophoraceae } & Rhizophora & $\begin{array}{l}\text { Rhizophora apiculata } \\
\text { Rhizophora mucronata } \\
\text { Rhizophora stylosa }\end{array}$ & Sedang (Moderate) \\
\hline & Bruguiera & $\begin{array}{l}\text { Bruguiera parviflora } \\
\text { Bruguiera gymnorrhiza }\end{array}$ & Sedang (Moderate) \\
\hline & Ceriops & $\begin{array}{l}\text { Ceriops tagal } \\
\text { Ceriops decandra }\end{array}$ & Sedang (Moderate) \\
\hline Rubiaceae & Scyphiphora & Scyphiphora hydrophyllacea & Terbatas (Limited) \\
\hline Sonne ratiace ae & Sonneratia & $\begin{array}{l}\text { Sonneratia alba } \\
\text { Sonneratia caseolaris } \\
\text { Sonneratia acida }\end{array}$ & Melimpah (Abundance) \\
\hline Sterculiaceae & Heritiera & Heritiera littoralis & Terbatas (Limited) \\
\hline
\end{tabular}

yang rendah di semua kecamatan. Untuk mengatasinya dengan mengaplikasikan pupuk urea yang dapat menurunkan rasio $\mathrm{C}: \mathrm{N}$ tanah dan mempercepat proses dekomposisi bahan organik. Pada tanah tambak yang kandungan liatnya lebih besar $60 \%$ dan bahan organiknya lebih rendah dari $8 \%$ disarankan mengaplikasikan pupuk kandang sebagai sumber bahan organik. Pemberian pupuk kandang ke tambak, dapat mempercepat laju pertumbuhan pakan alami. Keduanya penting untuk kegiatan budidaya tambak tradisional dan tradisional plus. Pupuk urea dan TSP (SP36) yang diaplikasikan yaitu $150 \mathrm{~kg}$ dan $75 \mathrm{~kg} / \mathrm{ha}$, pupuk kandangnya 1-2 ton/ha.

Tambak di Kabupaten Gresik, sebagian besar tergenang artinya dalam kondisi tereduksi (anaerob), adanya lumpur hitam $\mathrm{H}_{2} \mathrm{~S}$, amonia, dan metan yang toksik terhadap udang dan ikan. Hanya tambak mangrove di 


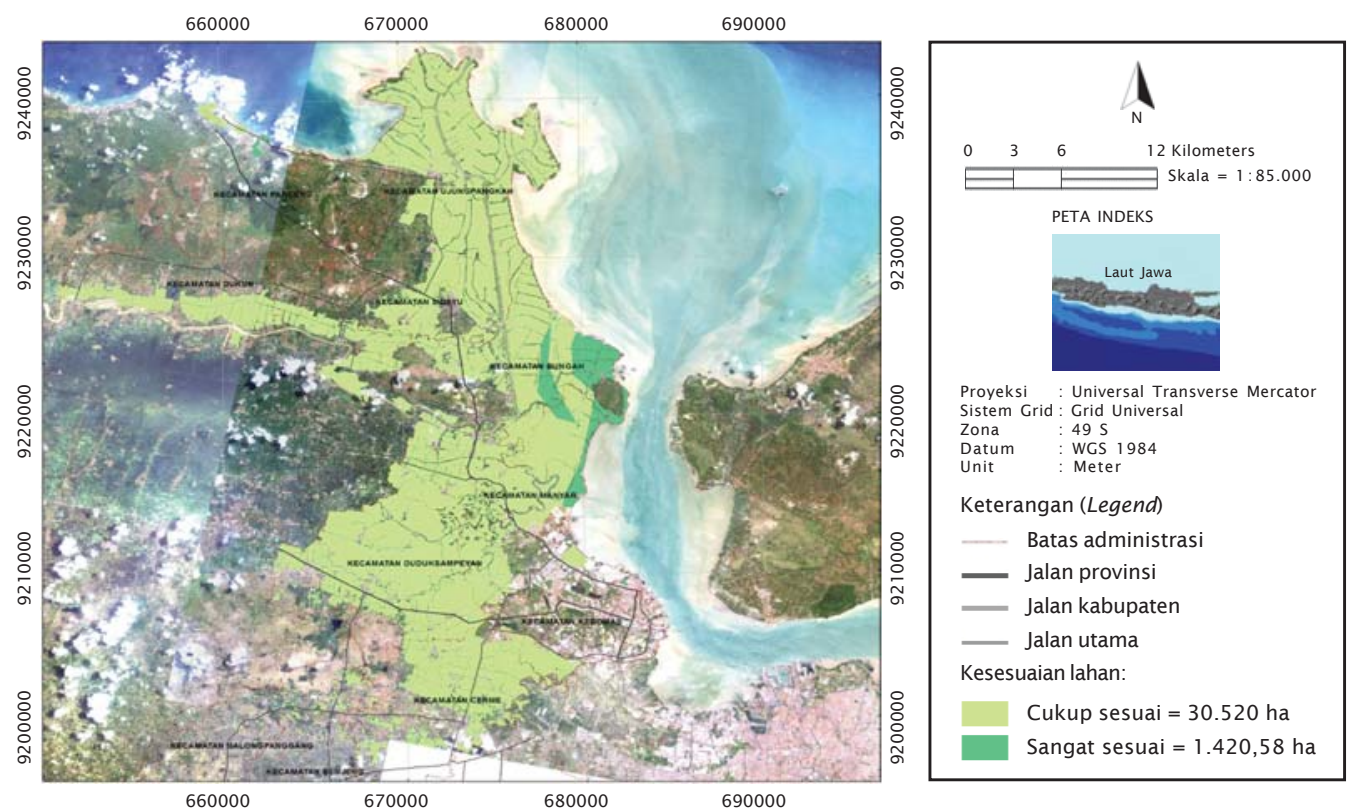

Gambar 3. Peta kesesuaian lahan budidaya ikan bandeng (Chanos-chanos Forsk.) di tambak di Kabupaten Gresik Provinsi Jawa Timur

Figure 3. Map of land suitability for milk fish (Chanos-chanos Forsk.) culture in brackishwater pond at Gresik Regency East Java Province

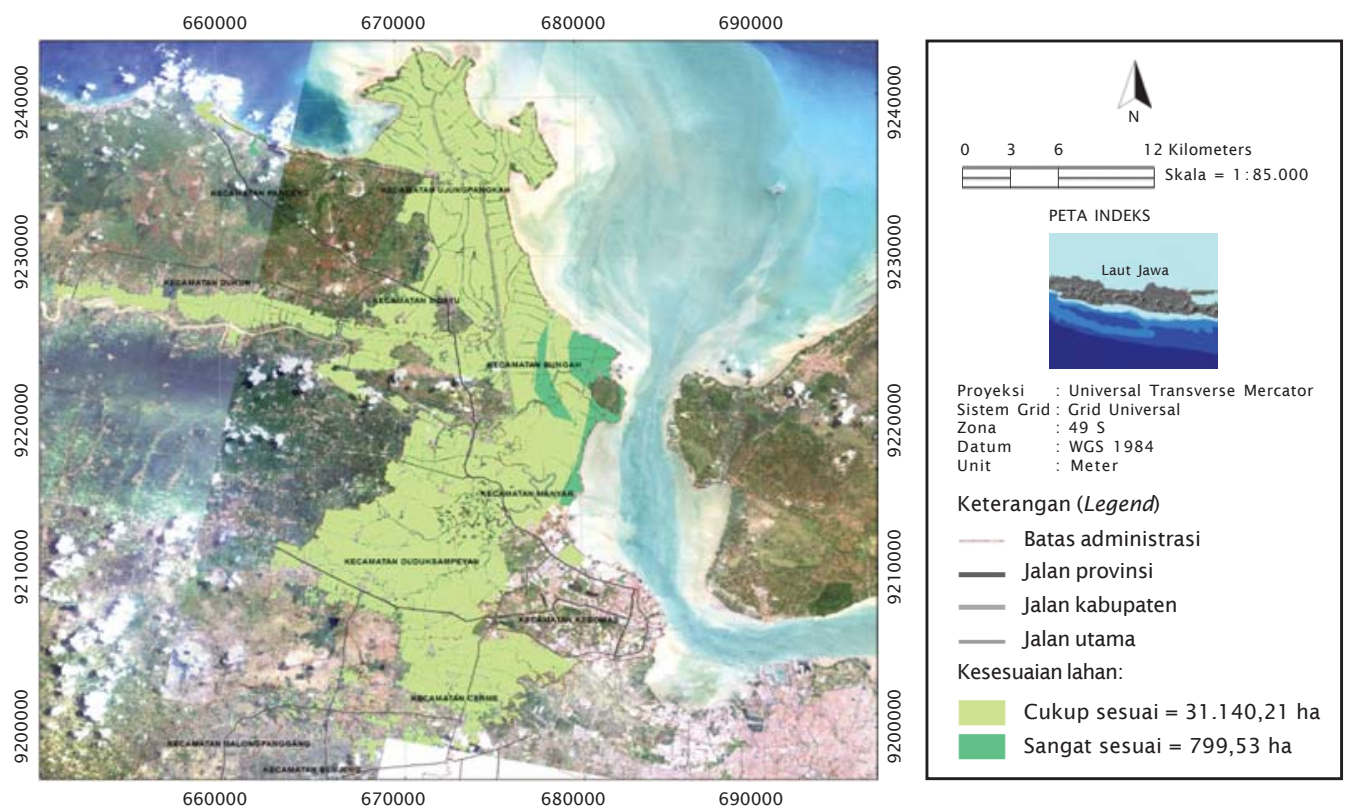

Gambar 4. Peta kesesuaian lahan budidaya udang vaname (Litopnaeus vannamei) di tambak di Kabupaten Gresik, Provinsi Jawa Timur

Figure 4. Map of land suitability for vaname shrimp (Litopnaeus vannamei) in brackishwater pond at Gresik Regency East Java Province 
Kecamatan Dukun memiliki kandungan besi feri $\left(\mathrm{Fe}^{3+}\right)$ tanah yang tinggi $(5.235,0 \mathrm{mg} / \mathrm{L})$ dari hasil oksidasi pirit penyebab kemasaman tanah. Cara mengurangi kemasaman, besi, dan unsur beracun di tambak dengan remediasi yaitu pengeringan, perendaman, pembilasan, dan pengapuran. Pengeringan tambak selama 2 minggu untuk mengoksidasi pirit, perendaman selama 1-2 hari untuk melarutkan dan menetralisir kemasaman, dan pembilasan untuk membuang hasil oksidasi dan unsur beracun diulang 2-3 kali, pengapuran untuk meningkatkan derajat kemasaman dan unsur hara makro serta memperbaiki struktur tanah. Untuk mengurangi besi fero $\left(\mathrm{Fe}^{2+}\right)$ pada budidaya tambak yang sumber airnya dari tanah yaitu air tanah dipompa, ditampung dalam petakan tandon, diaerasi dan dimasukkan ke petakan tambak.

\section{KESIMPULAN DAN SARAN}

Karakteristik lahan di Kabupaten Gresik yaitu topografi pantainya dengan elevasi rendah, lautnya terbuka dan dangkal, tambaknya hasil konversi mangrove, rawa, dan sawah serta sebagian tambak dan sawah dialihfungsikan menjadi lokasi pemukiman dan industri.

Hasil analisis kesesuaian lahan, tambak udang vaname di Kabupaten Gresik saat ini seluas 31.939 ha, yang sangat sesuai (kelas S1) 799 ha di Kecamatan Bungah, dan yang cukup sesuai (kelas S2) 31.140 ha, tersebar di Kecamatan Ujung Pangkah, Sidayu, Manyar, Duduk Sampeyan, dan Kecamatan Cerme.

Tambak ikan bandeng di Kabupaten Gresik saat ini seluas 31.940 ha, yang sangat sesuai (kelas S1) 1.420 ha terdapat di Kecamatan Bungah dan Manyar, dan yang cukup sesuai (kelas S2) 30.520 ha, tersebar di Kecamatan Ujung Pangkah, Sidayu, Duduk Sampeyan, dan Kecamatan Cerme. Lahan tambak yang sangat sesuai untuk kegiatan budidaya udang vaname atau ikan bandeng disarankan menggunakan teknologi semi intensif sampai intensif dan yang cukup sesuai untuk teknologi tradisional sampai semi intensif.

Lahan tambak di Kabupaten Gresik umumnya tergenang, disarankan perbaikan tanah dengan tahapan pengeringan, perendaman, pembilasan dan pengapuran. Bahan organik tanah dan $\mathrm{N}$ total tanah tambak yang rendah, disarankan pemberian pupuk kandang dan urea sebagai sumber bahan organik dan nitrogen yang dapat memperbaiki struktur tanah.

\section{DAFTAR ACUAN}

Anonim. 2009. Laporan Tahunan 2009. “Terwujudnya Pengelolaan Sumberdaya Kelautan, Perikanan dan Peternakan Secara Profesional Menuju Masyarakat Sejahtera". Dinas Kelautan, Perikanan, dan Peternakan Kabupaten Gresik, $78 \mathrm{hlm}$.

Anonim. 2011. Budidaya Air Payau. http:// www.pasuruankab.go.id/potensi-46budidaya-air-payau.html. [Diakses 25/11/ 2012].

Ahmad, T., Ratnawati, E., \& Yakob, M.J.R. 2009. Budidaya Bandeng Secara Intensif. PT. Penebar Swadaya, Anggota Ikapi, Jakarta, $96 \mathrm{hlm}$.

Bengen, D.G. 2004. Pedoman Teknis Pengenalan dan Pengelolaan Ekosistem Mangrove. Pusat Kajian Sumberdaya Pesisir dan Lautan, Institut Pertanian Bogor, Bogor, 59 hlm.

Blaso, F. 1984. Taxonomic considerations of the mangrove species. In: Snedaker, S.C., and Snedaker, J.G. (Eds.), The Mangrove Ecosystems: Research Methods. UNESCO, Bungay, p. 81-113.

Bouyoucos, C.J. 1962. Hydrometer method improved for making particle size analysis of soils. Agronomy Journal, 54: 464-465.

Bray, W.A., Lawrence, A.L., \& Leung-Trujillo, J.R. 1994. The effect of salinity on growth and survival of Penaeus vannamei with observations on the interaction of IHHN virus and salinity. Aquaculture, 122: 133-146.

Boyd, C.E., Wood, C.W., \& Thunjai, T. 2002. Aquaculture Pond Bottom Soil Quality Management. Oregon State University. Corvallis, Oregon, $41 \mathrm{pp}$.

Boyd, C.E. 2008. Pond bottom soil analysis. Global Aquaculture Advocate September/October, p. 91-92.

Chanratchakool, P., Turnbull, J.F., Funge-Smith, S., \& Limsuwan, C. 1995. Health Management in Shrimp Ponds. Second edition. Aquatic Animal Health Research Institute, Department of Fisheries, Kasetsart University Campus, Bangkok, 111 pp.

Clark, J.R. 1992. Integrated Management of Coastal Zones. FAO Fisheries Technical Paper No. 327. United Nations-FAO, Rome, $167 \mathrm{pp}$.

Effendi, H. 2003. Telaah Kualitas Air Bagi Pengelolaan Sumberdaya dan lingkungan Perairan. Penerbit Kanisius (Anggota IKAPI), Yogyakarta, $258 \mathrm{hlm}$. 
Ilyas, S., Cholik, F., Poernomo, A., Ismail, W., Arifudin, R., Daulay, T., Ismail, A., Koesoemadinata, S., Rabegnatar, I.N.S., Soepriyadi, H., Suharto, H.H., Azwar, Z.I., \& Ekowardoyo, S. 1987. Petunjuk Teknis bagi Pengoperasian Unit Usaha Pembesaran Udang Windu. Pusat Penelitian dan Pengembangan Perikanan, Jakarta, $100 \mathrm{hlm}$.

Hasnawi \& Mustafa, A. 2010. Karakteristik, kesesuaian, dan pengelolaan lahan untuk tambak budidaya di Kabupaten Luwu Utara Provinsi Sulawesi Selatan. Jurnal Riset Akuakultur. Pusat Penelitian dan Pengembangan Perikanan Budidaya, Badan Penelitian dan Pengembangan Kelautan dan Perikanan, Jakarta, 3(5): 449-463.

Hopkins, J.S., Stokes, A.D., Browdy, C.L., \& Sandifer, P.A. 1991. The relationship between feeding rate, padlle wheel rate and expected dawn dissolved oxygen in intensive shrimp ponds. Aquacultural Engineering, 10: 281-290.

Karthik, M., Suri, J., Saharan, N., \& Biradar, R.S. 2005. Brackhiswater aquaculture site selection in Palghar Taluk, Thane District of Maharashtra, India, using the techniques of remote sensing and Geographical Information System. Aquacultural Engineering, 32: 285-302.

Kementerian Lingkungan Hidup (KLH). 2004. Keputusan Menteri Negara Kependudukan dan Lingkungan Hidup, No. 51 tahun 2004, tanggal 8 April 2004 tentang Baku Mutu Air Laut. Kementerian Lingkungan Hidup, Jakarta, $11 \mathrm{hlm}$.

Melville, M.D. 1993. Soil Laboratory Manual. School of Geography, The University of New South Wales, Sydney, 74 pp.

Menz, A. \& Blake, B.F. 1980. Experiments on the growth of Penaeus vannamei Boone.
Journal of Experimental Marine Biology and Ecology, 48: 99-111.

Parsons, T.R., Maita, Y., \& Lalli, C.M. 1989. A Manual of Chemical and Biological Methods for Seawater Analysis. Pergamon Press, Oxford, 173 pp.

Perez, O.M., Ross, L.G., Telfer, T.C., \& Del Campo Barquin, L.M. 2003. Water quality requirements for marine fish cage site selection in Tenerife (Canary Islands): predictive modelling and analysis using GIS. Aquaculture, 224: 51-68.

Poernomo, A. 1988. Pembuatan Tambak Udang di Indonesia. Seri Pengembangan No. 7. Departemen Pertanian, Badan Penelitian dan Pengembangan Pertanian, Balai Penelitian Perikanan Budidaya Pantai, Maros, 30 hlm.

Poernomo, A. 1989. Faktor lingkungan dominan pada budidaya udang intensif. Dalam Bittner, A. (ed.), Budidaya Air. Yayasan Obor Indonesia, Jakarta, hlm. 66-120.

Poernomo, A. 1992. Pemilihan Lokasi Tambak Udang Berwawasan Lingkungan. Pusat Penelitian dan Pengembangan Perikanan, Jakarta, $40 \mathrm{hlm}$.

Reid, G.K. 1961. Ecology Inland Water Estuaries. Rein Hald Published Co. New York, 37 pp.

Sulaeman, Suparto, \& Eviati. 2005. Petunjuk Teknis Analisis Kimia Tanah, Tanaman Air, dan Pupuk. Dalam: Prasetyo, B.H. Santoso, D., dan Widowati, L.R. (Eds.). Balai Penelitian Tanah, Bogor, $136 \mathrm{hlm}$.

Widigdo, B. 2003. Permasalahan dalam budidaya udang dan solusinya. Jurnal IImu-ilmu Perairan dan Perikanan Indonesia, 10(1): 18 23. 